\title{
Desafios, Possibilidades e Estratégias para a Inserção de Pessoas Com Deficiência no Mercado de Trabalho e a (Náo) Efetividade da Lei de Cotas $^{1}$
}

Challenges, Possibilities and Strategies for the Insertion of PeOple With DisABILITIES IN THE LABOR MARKET AND THE (NON) EFFECTIVENESS OF THE QUOTA LAW

Ana Luísa Polizel LIBARDI²

Pedro Bordini FALEIROS ${ }^{3}$

Clemente, C. A., \& Shimono, S. O. (2015). Trabalho de pessoas com deficiência e Lei de Cotas: Invisibilidade, resistência e qualidade da inclusão. São Paulo: Edição dos Autores.

Carlos Clemente Aparício, formado em Administração de Empresas com especialização em Recursos Humanos e Didática do Ensino Superior, concluiu Bacharelado Interdisciplinar em Ciências do Trabalho da Escola DIEESE de Ciências do Trabalho. É também vice-presidente do Sindicato dos Metalúrgicos de Osasco e Região, e coordenador do Espaço da Cidadania.

Sumiko Oki Shimono, formada em Psicologia pela Universidade de São Paulo (USP), é especialista em Educação Inclusiva pela Pontifícia Universidade Católica de São Paulo (PUC-SP), mestre em Educação pela Faculdade de Educação da USP. Atuou em instituiçóes especializadas e empresas de consultoria na área da deficiência, e é colaboradora voluntária do Espaço da Cidadania.

O livro, apresentado em nove capítulos, é um recorte de uma pesquisa realizada pelos próprios autores. O seu principal objetivo é apresentar e discutir que o obstáculo central de um trabalho digno das pessoas com deficiência permanece sendo o preconceito cultural e a desinformação. Além disso, os autores também denunciam que os direitos dessas pessoas são ocultos, encobertos da sociedade e por superiores que deveriam ter uma melhor orientação sobre a Lei de Cotas.

No primeiro capítulo - "Apresentação" -, os autores anunciam o tema central, de modo a destacar que, segundo dados do Censo do Instituto Brasileiro de Geografia e Estatística (IBGE, 2010), as pessoas com deficiência estáo inseridas em várias ocupações, porém como

\footnotetext{
${ }^{1}$ http://dx.doi.org/10.1590/s1413-65382519000300011

${ }^{2}$ Mestranda do Programa de Pós-Graduação em Psicologia. Universidade Federal de São Carlos (UFSCar), Piracicaba-SP. analuisaplibardi@gmail.com. Piracicaba/São Paulo/Brasil. ORCID: https://orcid.org/0000-0002-8766-973X

${ }^{3}$ Docente do curso de Psicologia da Universidade Metodista de Piracicaba (UNIMEP). pbfaleiros@gmail.com. Piracicaba/São Paulo/Brasil. ORCID: https://orcid.org/0000-0003-3368-1415
} 
empregados. Também é apresentado um recorte do conteúdo da pesquisa acadêmica exibida na Escola DIEESE de Ciências do Trabalho em 2015, intitulada Lei de Cotas para o Trabalho de Pessoas com Deficiência - Análise e fundamentação dos principais argumentos favoráveis e contrários ao seu cumprimento. Com base nessa pesquisa, os autores trazem uma análise crítica de quatro argumentos utilizados contra o exposto pela Lei, a saber: 1) número insuficiente de pessoas com deficiência para atender à Lei; 2) falta de capacitação profissional; 3) pessoas com deficiência não querem trabalhar porque têm medo de perder o Benefício de Prestaçáo Continuada (BPC); e 4) restrição de postos de trabalho devido ao risco que representam para as pessoas com deficiência.

No segundo capítulo, os autores descreveram sobre a metodologia utilizada na pesquisa. Em um primeiro momento, foi feita uma busca de fontes de informação, como: órgãos oficiais, entidades especializadas, entrevistas com as pessoas com deficiências, oficinas, debates e outras; desse modo, a importância seria em constituir um banco de dados sobre o tema e, também, identificar os desafios implicados. Para tal, os autores realizaram uma revisão bibliográfica para investigar o tema referente à deficiência e como este aparece ao longo da história. Além disso, analisaram o ponto central da bibliografia sobre o contexto atual da inclusão. Os autores buscaram, também, outras fontes de dados, tais como: Censos do IBGE de 2000 a 2010; Rais de 2007 a 2013; Registros do Ministério do Trabalho e Emprego para fiscalização e controle da Lei de Cotas de 2000 a 2005, entre outras, para refutar os argumentos contrários à Lei de Cotas.

O cenário da inclusão no Brasil é apresentado e discutido no terceiro capítulo. Os autores recorreram a estudos para fazer uma discussão sobre a questão do preconceito, como também do problema central em relação à entrada de pessoas com deficiência no trabalho e na sociedade, com interface à Lei de Cotas. Ainda, nesse capítulo, é perceptível a discrepância de entendimento de alguns estudos relatados no livro. Alguns acreditam que deveria existir a flexibilização, isto é, outras formas de ocupação no trabalho para essas pessoas, enquanto outros acreditam que o cumprimento à Lei de Cotas seria essencial como eficiência da fiscalização, ou ainda mais, que a atitude primordial deveria ser descontruir o preconceito presente nas relaçóes de trabalho.

Já o objetivo do quarto capítulo refere-se à análise dos autores sobre os argumentos para o não cumprimento da Lei de Cotas. O primeiro argumento apresentado é de que: "Não há pessoas com deficiência em número suficiente para ocupar as vagas previstas na Lei de cotas". Tal argumento é considerado por Clemente e Shimono como uma justificativa comumente usada por empresas, órgãos de fiscalização, Poder Judiciário, mídia, movimento sindical e sociedade brasileira, e consolida a falta de acesso das pessoas com deficiência ao trabalho, pois essas alegaçóes frequentemente são acolhidas. O segundo argumento é de que: "A formação das pessoas com deficiência é incompatível com as necessidades do mercado de trabalho". Os autores alegam que esse tipo de desculpa aparece nos confrontos entre empresas e Ministério do Trabalho, como também com o Ministério Público do Trabalho, na mídia, em pesquisas de opinião com profissionais de Recursos Humanos e gestores de empresas, na mesa de negociações trabalhistas, entre outros. 
A justificativa utilizada sobre a falta de qualificação profissional dessas pessoas é recorrente desde o ano de 2000 e permanece até os dias de hoje, de acordo com os dados apontados em pesquisas. O terceiro argumento descrito é de que: "As pessoas com deficiência preferem receber o BPC da Assistência Social, em vez de disputar as vagas do trabalho formal" e é feito por oficiais fiscais, Procurador do MPT, petiçôes do Judiciário trabalhista e até por advocacias empresariais ou órgãos de representação empresariais. Essa alegação é feita com muita convicção por essas pessoas e instituiçóes, pois, segundo os autores, há inferências de que as próprias pessoas com deficiência escolhem não trabalhar a ganhar um recurso para ter o benefício continuado. Contudo, Clemente e Shimono consideram que esse argumento é insustentável, pois há dados que indicam mudanças a partir de 2007 que garantem a oportunidade de o beneficiário participar do mercado de trabalho e possivelmente retornar ao benefício. Ainda com a aprovação da Lei № 12.470, em 2011, tornou-se permissível uma pessoa com deficiência que até então recebia o BPC estar inserida, simultaneamente, no mercado de trabalho. O quarto e último argumento é de que: "Em muitos postos de trabalho há riscos que são proibitivos para as pessoas com deficiência”, em que essas mesmas pessoas e instituiçôes transferem a obrigação da contratação de pessoas com deficiência para o obstáculo à contratação.

Os autores denunciam que essas pessoas são excluídas para desempenhar funçóes relacionadas ao setor operacional, mesmo que tenham necessidades específicas que não as impedem de executar. As conclusóes da pesquisa são apresentadas no quinto capítulo, e as principais constataçóes identificadas pelos autores são: a) o preconceito é a principal barreira contra o trabalho digno das pessoas com deficiência; b) a Convenção sobre os Direitos das Pessoas com Deficiência, da Organização das Naçóes Unidas (ONU), que foi aprovada no Brasil em 2008, não é considerada pela sociedade e pelos juízes - estes que tinham de ter a responsabilidade e um melhor entendimento dela para conduzir os julgamentos relacionados à Lei de Cotas; c) a falta de concordância entre os estudos sobre a importância de haver ambientes de trabalhos inclusivos e o que de fato acontece na realidade, isto é, as pessoas com deficiência ainda são vistas como incapazes de ter uma vida profissional produtiva; d) a maioria da população adquire a deficiência durante a vida e tem experiência para contribuir na sociedade porque já contribuía antes de adquirir a deficiência; e) houve avanços nos últimos 30 anos no mundo e, também, no Brasil, sobre a questão da inclusão dessas pessoas dentro da sociedade. Entretanto, as leis referentes ao direito desses indivíduos no trabalho - por exemplo, a Lei de Cotas em diversos órgãos públicos - não vigoram de verdade ou distorcem algumas informações por preconceito às pessoas com deficiência.

No sexto capítulo, são discutidos os desafios e as estratégias de ação para a melhoria da qualidade da inclusão de pessoas com deficiência no mercado de trabalho. Os autores apresentam dados que confirmam que há 15 anos a Lei de Cotas começou a ser fiscalizada pelos órgãos, porém destacam que será necessário mais algum tempo para que de fato ela seja cumprida de forma eficaz. Para Clemente e Shimono, há desafios a serem enfrentados e superados, como a desinformação, o preconceito, as barreiras físicas e atitudinais. Somente assim será possível incluir as pessoas com deficiência no mercado de trabalho e garantir as condiçóes para que elas exerçam seu trabalho de forma digna. Ainda nesse capítulo, os autores salientam que esses desafios estão dentro das esferas empresarial, familiar e social. Eles fazem, também, uma reflexão sobre o tema, abordando os seguintes assuntos: a utilização da terminologia correta 
para se referir às pessoas com deficiência; a preparação das empresas em receber essas pessoas, e se existe qualidade na inclusão delas (mudança na cultura organizacional e a garantia de acessibilidade ao trabalho e ao desenvolvimento profissional); o papel da família e da instituição para que sejam orientados a estimularem e a incentivarem a autonomia e a independência deles, e os fatores que favorecem uma sociedade mais inclusiva. Ao final do sexto capítulo, os autores afirmam que a discussão do tema da inclusão deve ser mais abordado e deve envolver ativamente as pessoas que participam desse processo, pois, dessa forma, pode acontecer a promoção de uma avaliação crítica dos princípios, dos conceitos e das diretrizes que medeiam a prática, podendo, assim, melhorar cada vez mais a visão desse assunto em todos os âmbitos da sociedade.

O livro "Trabalho de pessoas com deficiência e Lei de Cotas: Invisibilidade, resistência e qualidade da inclusão" oferece uma relevante reflexão e contribuição em direção à inclusão de pessoas com deficiência dentro do mercado de trabalho. Com base em ampla pesquisa acadêmica, com artigos e depoimentos de especialistas e consultores comprometidos no debate sobre o sistema de cotas e a inclusão com qualidade, a obra caracteriza-se como imprescindível para desmistificar o preconceito e ampliar os avanços sobre a oportunidade de espaço no ambiente de trabalho para pessoas com deficiência. A importância do assunto tratado reflete a conscientização da luta pelo direito ao trabalho das pessoas com deficiência. A obra também orienta o olhar crítico dos indivíduos sobre o preconceito em relação ao pleno acesso da pessoa com deficiência no mercado de trabalho. Além disso, os autores proporcionam aos leitores um pensamento crítico dos principais assuntos relacionados à inclusão das pessoas com deficiência.

Cabe salientar que também é enfatizada a intensa e incessante luta pelo direito ao trabalho dessas pessoas, bem como a garantia do cumprimento da Lei de Cotas, que até então não acontece de fato. Ademais, é preciso pensar em estratégias e açóes para que as condiçóes de cidadania e de um trabalho decente e digno sejam respeitadas para essa população. O livro também contribui de forma significativa para a área da inclusão no Brasil, já que o tema não é discutido em sua devida necessidade, como também pela escassez de literatura dedicada a estudar a importância do assunto. Essa questão se torna fundamental para que especificamente aumente a possibilidade de mercado de trabalho para as pessoas com deficiência dentro da atual sociedade, esta que se encontra somente em seus estágios iniciais de processo de inclusão.

Desse modo, para que o processo vigore de fato, é preciso que esteja presente em todos os sistemas da sociedade, e que haja paciência para celebrar as conquistas e buscar espaço de luta para enfrentar os desafios que estarão presentes a todo o momento. De acordo com Maciel (2000), a inclusão das pessoas com deficiência em todos os âmbitos é incipiente, e há muito a que ser feito para que possa ser modificado o quadro de marginalização dessas pessoas.

Nesse sentido, o livro propóe estratégias de ação para possibilitar a melhoria da qualidade de inclusão no mercado de trabalho para essas pessoas, o que é um diferencial, pois, além de apontar os desafios, planeja ideias para que o leitor possa ter um pensamento crítico e perpetuar as ações propostas. Assim, não só dá o embasamento teórico, mas também contribui para a prática por meio de propostas de mudança que podem ser feitas em empresas (ex.: mudança na cultura organizacional e garantia de acessibilidade ao trabalho e ao desenvolvimento profissional), em instituiçóes especializadas (ex.: garantia do direito humano e do trabalho da pessoa com deficiência), a partir da visibilidade ao trabalhador com deficiência que é feito por 
intermédio do movimento sindical, como também a partir da garantia à inclusão em que há três grandes barreiras a serem desconstruídas: arquitetônica, comunicacional e atitudinal.

\section{REFERÊNCIA}

Instituto Brasileiro de Geografia e Estatística. Censo 2010. Recuperado em 3 de julho de 2019 de https:// censo2010.ibge.gov.br/.

Maciel, M. R. C. (2000). Portadores de deficiência: a questão da inclusão social. São Paulo em Perspectiva, 14(2), 51-56. ${ }^{4}$

Submetido em 06/05/2019

Aceito em 15/05/2019 
LIBARDI, A.L.P. \& FALEIROS, P.B. 